\title{
Effect of Silicon Particles on the EDM Characteristics of Al-Si Alloys
}

\author{
De-Chang Tsai *, Truan-Sheng Lui and Li-Hui Chen \\ Department of Materials Science and Engineering, National Cheng-Kung University, Tainan, 701 Taiwan, R.O. China
}

The second phase of the Aluminum-Silicon (Al-Si) alloy embedded in microstructure includes primary silicon particles and hypereutectic silicon particles. Variations in the area fraction of these silicon particles significantly influences Electro Discharge Machining (EDM) characteristics. The area fraction of these silicon particles is proportional to materials removal rate (MRR). Experimental data obtained using Scanning electron microscope (SEM) revealed that discharge craters were formed as a ridge on the EDMed surface. The increased average surface roughness $(R a)$ resulted in an increased EDM rate. The area fraction of second phase silicon particles, and the ridge density on the rapidly resolidified layer of the EDMed surface tended to increase. However, most silicon particles were found on the peaks on the sub-layer of the EDMed surface, formed by rapidly solidification of molten fluid during discharge melting. Therefore the presence of silicon particles in the rapidly resolidified layer was largely governed by the formation of discharge peaks. The formation of peaks was governed by EDM conditions and silicon content. The electrodes showed stable wear during EDM when the pulse duration exceeded $150 \mu$ s. Wear increased as the area fraction of silicon particles increased.

(Received July 23, 2001; Accepted December 3, 2001)

Keywords: electro discharge machining (EDM), aluminum-silicon, silicon particles, materials removal rate, ridges

\section{Introduction}

Al-Si alloys contain many acicular eutectic silicon particles in the $\alpha$-Al matrix within hypoeutectic composition range. As the silicon content rises to the hypereutectic level, primary silicon particles, except those in the acicular hypereutectic silicon phase, form rod-like and massive structures. ${ }^{1)}$ Al-Si alloys have potential in inject plastic forming molds, such alloys exhibit heat conductivity, anti-corrosion properties, wear resistively and have a low heat expansion coefficient. $^{2,3)}$

Typical EDM is known as Spark-Erosion Machining. This electro machining method is essential for cutting machining equipment used to inject plastic for manufacturing molds. Metal molds typically include hard-to-cut parts such as complex 3D curved faces and sharp angles. EDM is therefore very valuable in machining mold materials. The estimated discharge point temperature is many thousand degrees $\left({ }^{\circ} \mathrm{C}\right)$ in typical EDM, ${ }^{4)}$ to rapidly melt machined materials at the discharge point. The locally generated high-temperature sparks cause the surrounding kerosene to evaporate rapidly and its volume to expand. The high pressure generated by this inertia enclosure effect rapidly removes molten metals from the surface of machined materials. Studies on EDM characteristics primarily considers tool-steel alloys; experimental data related to the EDM characteristics of conductive ceramic and Ti alloys, ${ }^{5-9)}$ and the effects of compound phases on the EDM characteristics of $\mathrm{Al}$ alloys in terms of $\mathrm{SiC} / \mathrm{Al}$ compound materials. ${ }^{10)}$ Furthermore, Ramulu and Taya stated that the MRR of silicon carbide whiskers ( $\mathrm{SiCw}$ ) compound materials varied according to the volume fraction of second-phase SiCw. ${ }^{11)}$ We investigated the effect of spheroidal graphite heterogeneous second phase on the EDM characteristics of Fe-based materials. The variations in second-phase particles significantly increased $M R R$ values. $^{12,13)}$ This study used a range of 4-29 mass\% to change the silicon content in Al-Si alloy spec-

*Graduate Student, National Cheng-Kung University.

E-mail: tsai@mail.hit.edu.tw or z7408020@email.ncku.edu.tw imens; to clarify the effect of heterogeneous second phase on $M R R$ values, and to explore the influence of the area fraction of eutectic silicon particles and primary silicon particles on the EDM characteristics of Al-Si alloys.

\section{Experimental Procedures}

Commercial pure aluminum and pure silicon were melted in a high-frequency $30-\mathrm{kg}$ furnace. The molten metals were maintained at temperatures above that of the liquid phase line at 50 degrees $\left({ }^{\circ} \mathrm{C}\right)$, according to their different silicon contents. The molten metals were cast into $30 \times 100 \times 150 \mathrm{~mm}^{3}$ Y-shaped iron molds, following $20 \mathrm{~min}$ of argon degassing. Table 1 gives the chemical composition of each specimen. Figure 1 depicts the corresponding microstructures. Those Al-Si alloys specimens with 4-12 mass\% Si content exhibited hypoeutectic properties, determined by $\alpha$-Al and acicular eutectic silicon particles (Figs. 1(a)-(d)). In the 17-29 mass\% $\mathrm{Si}$ specimens, the rod-like and massive primary silicon phase increased with silicon content (Figs. 1(e)-(h)).

Figure 2 is an schematically depicts the experimental apparatus. Table 2 displays the experimental parameters of EDM. The variations in discharge current and pulse duration between the copper electrode and the specimen were observed using an oscilloscope. The estimated temperatures at the discharge point exceeded several thousand degrees $\left({ }^{\circ} \mathrm{C}\right)$ over the

Table 1 Chemical composition of the Al-Si alloys. (mass\%)

\begin{tabular}{cccc}
\hline Designation & $\mathrm{Si}$ & $\mathrm{Fe}$ & $\mathrm{Al}$ \\
\hline $\mathrm{Al}-4 \mathrm{Si}$ & 4.08 & 0.13 & Bal. \\
$\mathrm{Al}-7 \mathrm{Si}$ & 7.42 & 0.14 & Bal. \\
$\mathrm{Al}-11 \mathrm{Si}$ & 10.5 & 0.12 & Bal. \\
$\mathrm{Al}-12 \mathrm{Si}$ & 12.1 & 0.18 & Bal. \\
$\mathrm{Al}-17 \mathrm{Si}$ & 16.8 & 0.16 & Bal. \\
$\mathrm{Al}-20 \mathrm{Si}$ & 20.3 & 0.14 & Bal. \\
$\mathrm{Al}-25 \mathrm{Si}$ & 25.4 & 0.14 & Bal. \\
$\mathrm{Al}-29 \mathrm{Si}$ & 28.7 & 0.15 & Bal. \\
\hline
\end{tabular}



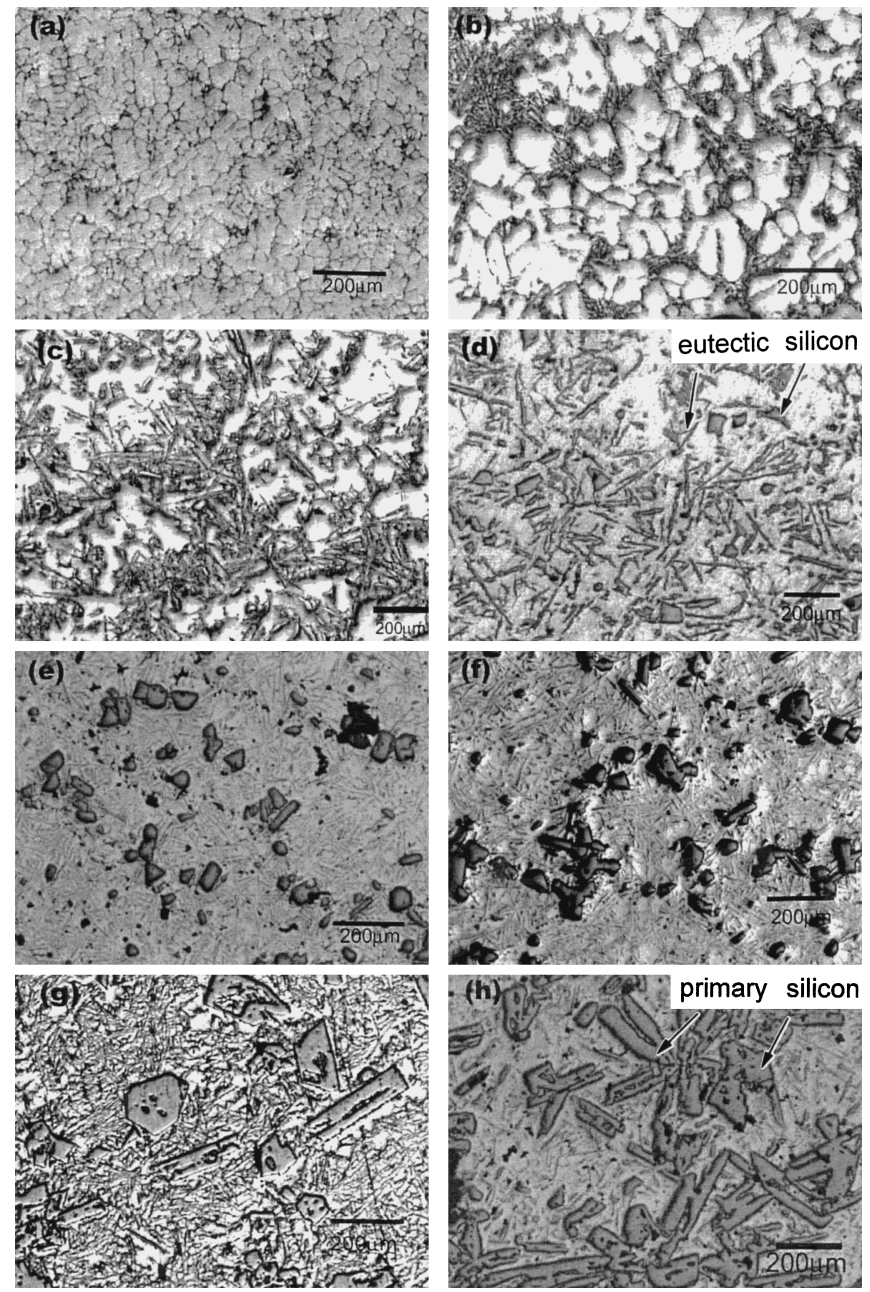

Fig. 1 Optical microstructure of Al-Si alloy: (a) 4Si, (b) 7Si, (c) 11Si, (d) $12 \mathrm{Si}$, (e) $17 \mathrm{Si}$, (f) $20 \mathrm{Si}$, (g) $25 \mathrm{Si}$, (h) $29 \mathrm{Si}$.

Table 2 Process parameter of EDM.

\begin{tabular}{ll}
\hline Electrode materials & $\mathrm{Cu}$ \\
Electrode polarity & Positive \\
Specimen materials & $\mathrm{Al}-\mathrm{Si}$ \\
Working area $\left(\mathrm{mm}^{2}\right)$ & 100 \\
Discharge current $\mathrm{Ip}(\mathrm{A})$ & 20 \\
Pulse duration $\tau_{\mathrm{p}}(\mu \mathrm{s})$ & $20-1000$ \\
Duty factor* & 0.67 \\
Dielectric fluid & Kerosene \\
Fluid pressure $\left(\mathrm{kg} / \mathrm{mm}^{2}\right)$ & 0.7 \\
\hline
\end{tabular}

*Duty factor is the ratio of pulse duration to a total pulse period.

pulse duration, causing rapid melting and evaporation on the surface. Part of the molten metal was then flushed away by high-pressure kerosene. Nodular machining debris was formed by rapid solidification of the flushed molten metal. The weight losses per unit time of the specimen and the copper electrode due to machining were determined, and defined as the materials removal rate $(M R R, \mathrm{~kg} / \mathrm{s})$ and the electrodes wear rate $(E W R, \mathrm{~kg} / \mathrm{s})$.

Since the remaining molten metal not flushed away by the kerosene rapidly solidified on the specimen surface during the pulse-off time, the surface roughness of the resulting EDM craters was measured with a surface roughness measurer, and

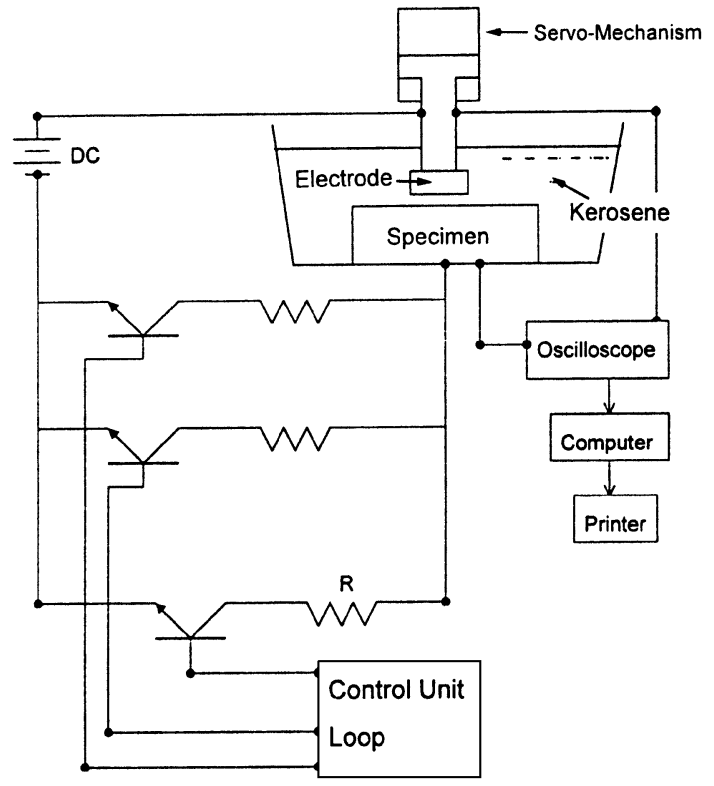

Fig. 2 Schematic illustration of EDM.

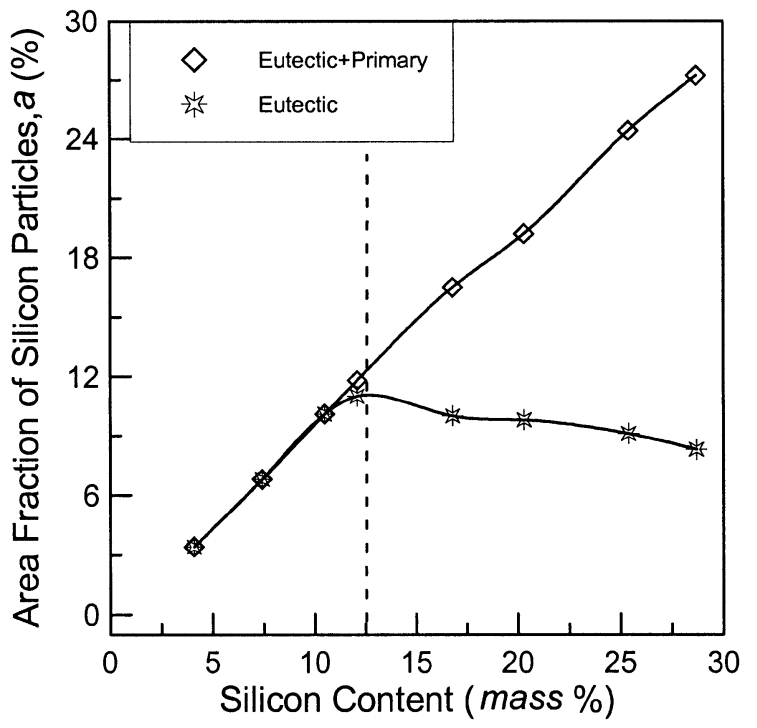

Fig. 3 Relationship between silicon content and area fraction of silicon particles.

stated as an average roughness $(R a)$. The EDM craters on the machined surface were characterized by ridge density. The high temperature formed the craters on the solidified layer on the specimen surface and discharge impact caused due to the discharge arc in EDM. The surface roughness measurer can record the tracks on the craters. The points are defined as ridges if the ridge height roughness exceeds $10 \mu \mathrm{m}$. Ridge density is the average number of ridges per unit area $\left(\right.$ no. $\left./ \mathrm{mm}^{2}\right)$. The features of the EDMed surface and sub-layer on which discharge craters were found, were examined using a SEM.

\section{Results}

\subsection{Quantitative examination of microstructure and the effect of silicon content on EDM conditions}

Figure 3 shows that the area fraction of acicular eutectic silicon particles in hypoeutectic Al-Si alloys increased with sil- 
icon content. When the silicon content increased to the level of eutectic composition, the area fraction of acicular eutectic silicon particles reached a maximum. Later, when the silicon content increased to the hypereutectic composition, the quantity of acicular eutectic silicon particles crystallized, slightly decreased as rod-like and massive primary silicon particles were crystallized out. Consequently, as shown in Fig. 3, the total quantity of acicular eutectic and primary silicon particles increased with silicon content. Figures 4(a) and 4(b) show that the MRR and the machined surface $R a$ of both the Al-12Si specimen close to the eutectic composition and the Al-29Si specimen at hypereutectic composition, were significantly affected by the pulse duration, when the fixed EDM current was $20 \mathrm{~A}$ and the duty factor was 0.67 . The MRR and $R a$ both increased with pulse duration. $M R R$ and $R a$ markedly decreased from their peak values with pulse duration when the pulse duration was over $350 \mu \mathrm{s}$. Electrode wear is inevitable during EDM, and Fig. 4(c) shows that the EWR in the initial stage initially decreased rapidly as pulse duration increased. The phenomenon was defined as the first stage during the experiment. The $E W R$ remained at $8.2 \times 10^{-8} \mathrm{~kg} / \mathrm{s}$ when the pulse duration increased to over $150 \mu \mathrm{s}$. In this second stage, $M R R$ tended to increase significantly as the pulse duration increased to $350 \mu \mathrm{s}$. In the third stage, carbon accumulated on
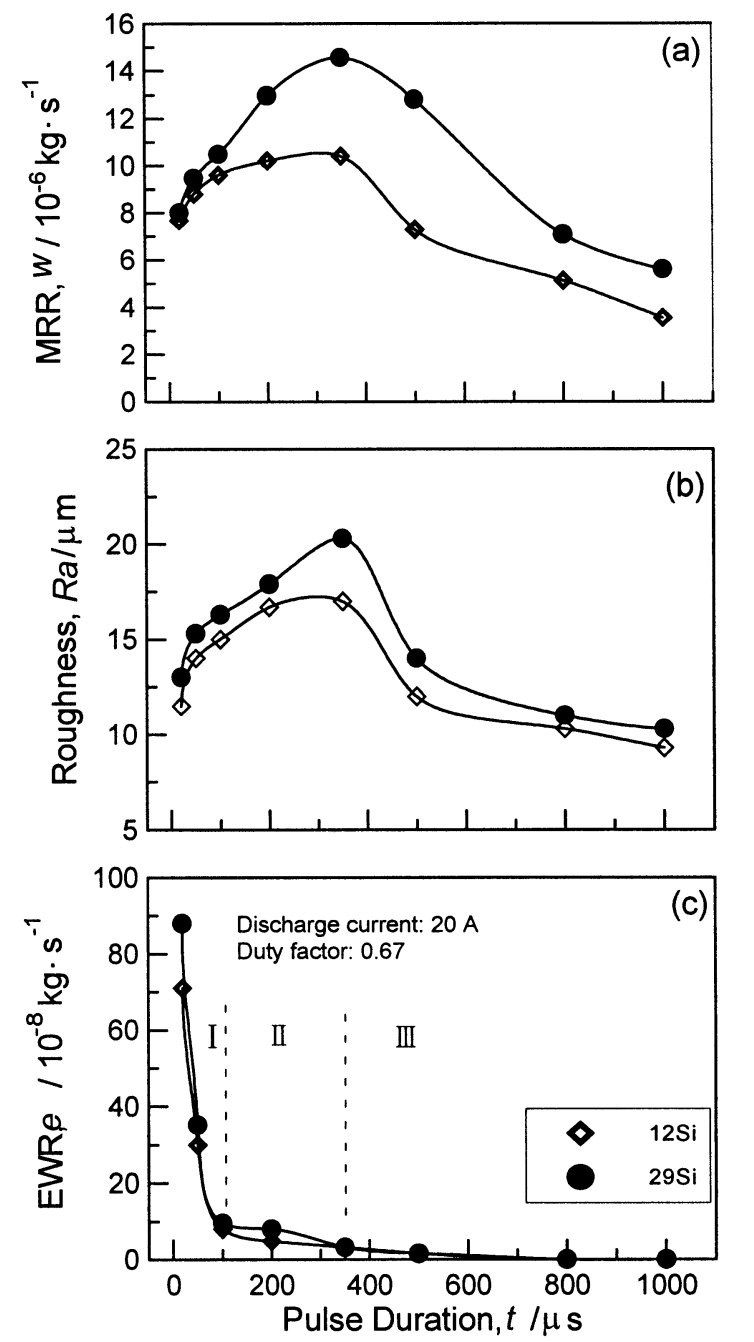

Fig. 4 Relationships between pulse duration, and (a) materials removal rate, (b) average roughness, and (c) electrodes wear rate. the electrode surface, leading to much lower EWR. MRR was significantly slowed with increased pulse duration.

\subsection{Effect of silicon particles content on the EDM char- acteristics}

Figure 5 displays the relationship between variations in the area fraction of silicon particles and the EDM characteristics of each Al-Si alloy specimen. Under any given EDM conditions (pulse duration: $350 \mu \mathrm{s}$ ), MRR tended to significantly increase with increasing the area fraction of silicon particles. In addition, $E W R$ tended to increase with the area fraction of silicon particles.

During the pulse-off stage of the EDM process, the molten metal in the area in which discharged sparks temporarily disappeared, rapidly solidified and formed a rapidly resolidified layer. Quantitative clarification is required as the formation of this rapidly resolidified surface layer is governed by EDM. In particular, the ridges formed on the discharge craters determine the $M R R$ of the material. Figure 6 lists the results concerning the rapidly resolidified layer following EDM
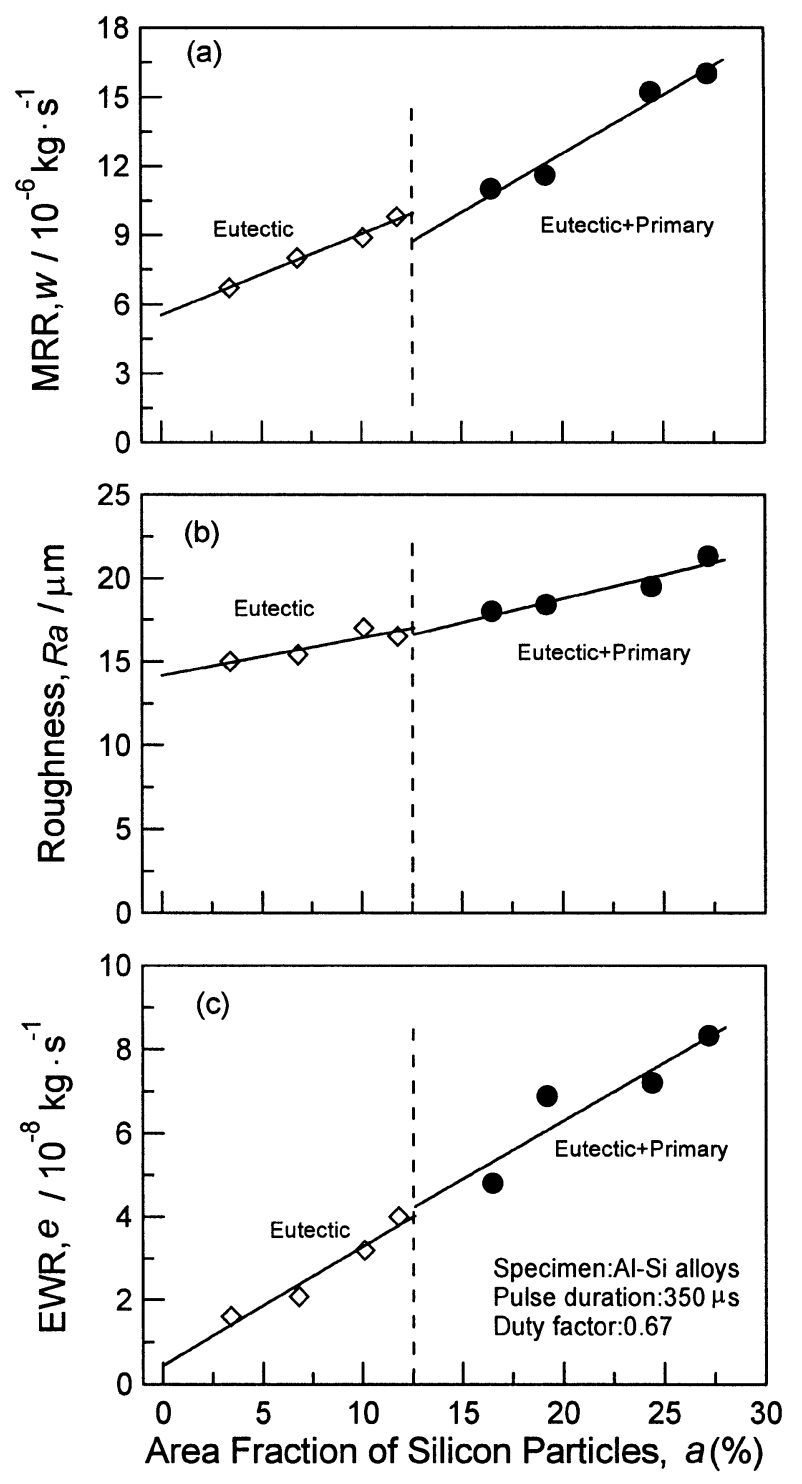

Fig. 5 Relationships between area fraction of silicon particles, and (a) materials removal rate, (b) average roughness, and (c) electrodes wear rate. 

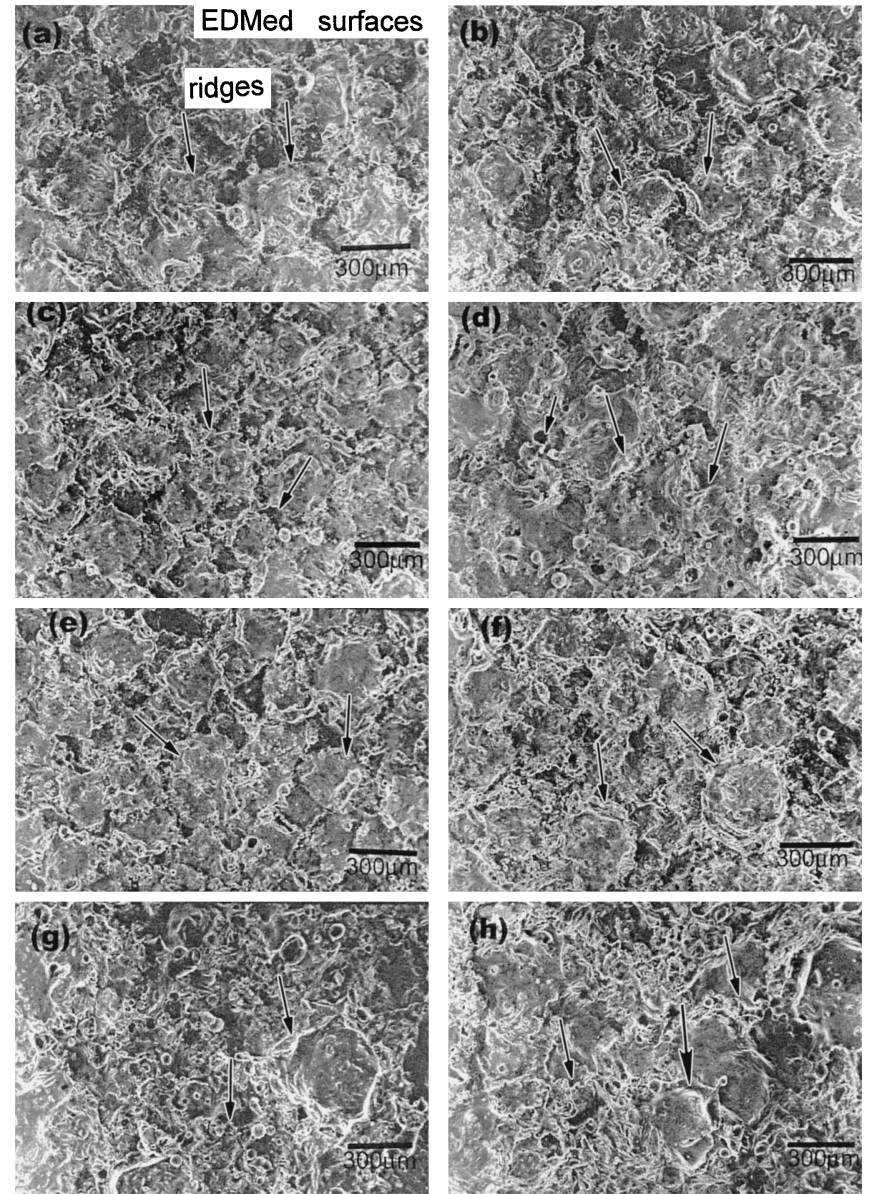

Fig. 6 EDMed surfaces: (a) 4Si, (b) 7Si, (c) $11 \mathrm{Si}$, (d) $12 \mathrm{Si}$, (e) $17 \mathrm{Si}$, (f) $20 \mathrm{Si}$, (g) 25Si, (h) 29Si.

under a specified EDM condition, pulse duration: $350 \mu \mathrm{s}$. Figures 6(a)-(d) display the EDMed surfaces of specimens with the hypoeutectic composition in which the microstructure contains acicular eutectic silicon particles. Figures 6(e)(h) display the EDMed surfaces of specimens in which the microstructure contains rod-like and massive primary silicon particles. The aforementioned specimens all possessed ridges on their EDMed surfaces and the ridges increased with silicon content. However, it is difficult to distinguish the EDMed surface from the SEM evidence. The craters on the EDMed surface were first investigated with the surface roughness measurer to quantitatively measure the average ridge number of discharge craters, and the moving tracks of the probe were recorded. Figure 7 shows that under specific EDM conditions, a specimen with the highest silicon content (29Si) presents the highest average ridge number following EDM. Figure 8 shows that when the silicon content increased, the ridge density value on the EDMed surface markedly increased with the area fraction of eutectic and primary silicon particles.

\subsection{Formation of ridge point on rapidly resolidified layer}

The above experimental results indicate that an increased area fraction of second-phase silicon particles facilitates $M R R$. The effect is closely related to the ridge point density of the rapidly resolidified layer on the EDMed surface. The ridges formed on this surface and sub-surface confirms to the rapidly resolidified structure (Fig. 9), in which many acicu-
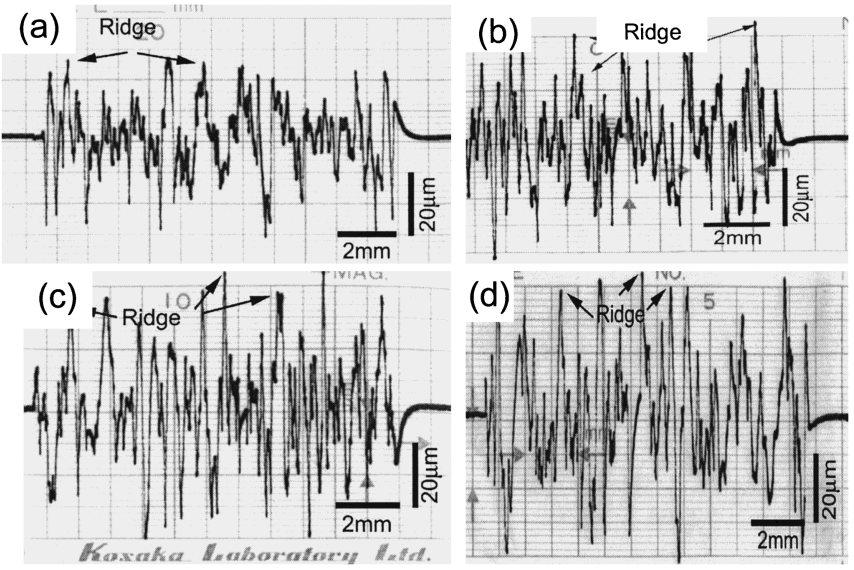

Fig. 7 EDMed sufaces detected by surface roughness Measurer in the different silicon content: (a) $4 \mathrm{Si}$, (b) $12 \mathrm{Si}$, (c) $20 \mathrm{Si}$, (d) $29 \mathrm{Si}$.

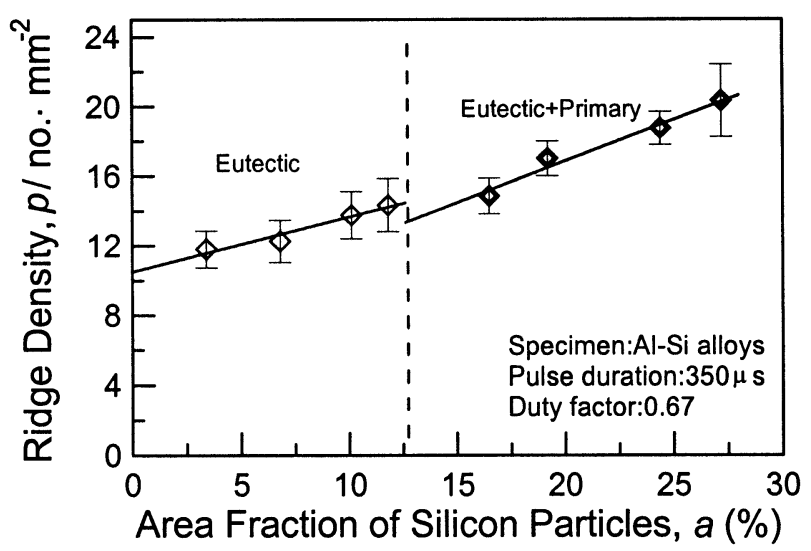

Fig. 8 Relationship between ridge density and area fraction of silicon particles.

lar, extremely fine, eutectics, rod-like, and massive primary silicon particles are buried (Figs. 9(e)-(f)). During melting and solidification, rate of formation of ridges in silicon particles increased with a high melting point $\left(1430^{\circ} \mathrm{C}\right)$ on the EDMed surface, due to the difference between the melting point of the $\alpha$-phase and that of the silicon phase. The Xray analysis of Fig. 10 proves that the amount of silicon near the ridges formed in re-solidification markedly increased with silicon content.

However, the oscilloscope graphic in Fig. 11 indicates that the frequency of discharge generated per unit time increased with silicon content of the specimens. Figure 12 shows that their discharge density is linearly related to ridge density. Increasing the area fraction of second-phase silicon, whether acicular eutectic or rod-like and massive primary silicon particles, promoted the generation of discharged sparks.

\section{Discussion}

The results show that varying EDM conditions and the area fraction of silicon particles influences the EDM efficiency of $\mathrm{Al}-\mathrm{Si}$ alloys. For a constant charging current (20A) and when the pulse duration increased, the incoming heat and discharge impact due to a single discharged spark promoted MRR. However, $M R R$ reached a peaked when the pulse duration was maintained for $350 \mu \mathrm{s}$. Beyond this peak value, $M R R$ was 

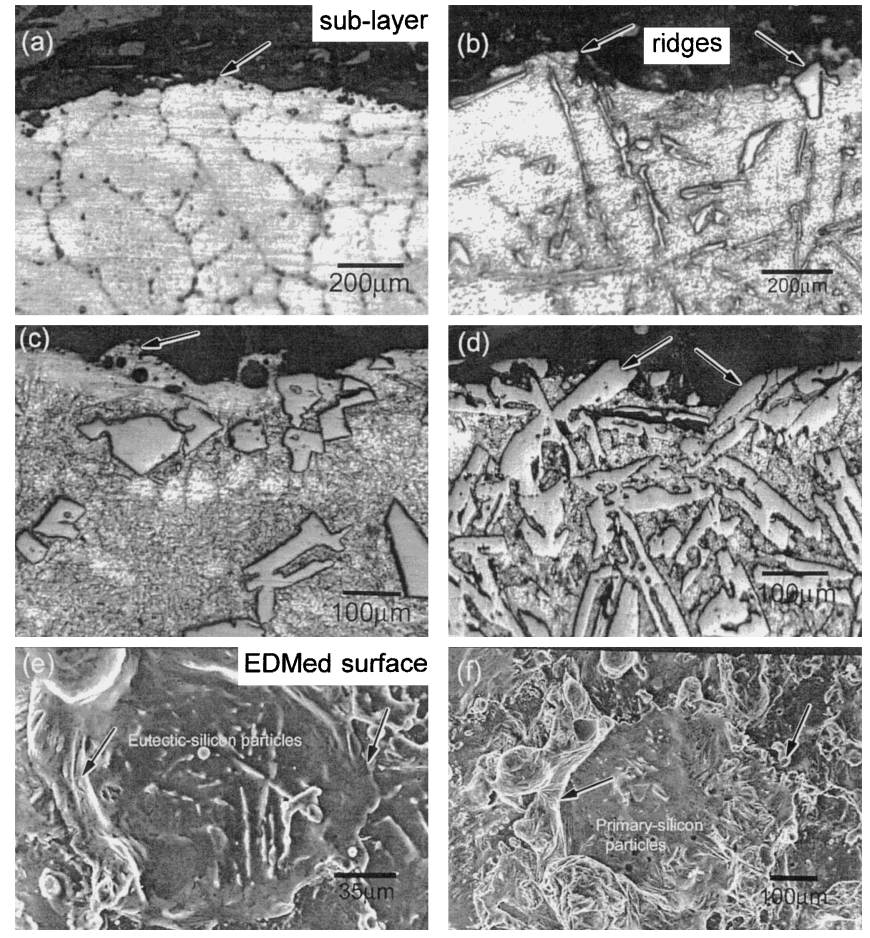

Fig. 9 EDMed sub-layers: (a) 4Si, (b) 12Si, (c) 20Si, (d) 29Si, and EDMed surfaces: (e) $12 \mathrm{Si}$, (f) $20 \mathrm{Si}$.

adversely affected by further prolonging the pulse duration. Previous studies show that this finding follows from the fact that both current density and discharge impact decrease as the area of the discharge craters increases, as the pulse is prolonged. Restated, discharge points tend to generate abnormal discharge arc (welding arc) when the charging energy density is reduced by a boundary constraint. Reduced the size of discharge craters, and increased their prevalence. Restated, smaller discharge craters increased the charging current density of the discharge area, and increased MRR. Accordingly, problems like carbon accumulation on the EDMed surface and increasingly difficult removal of machining debris resulted in MRR slowdown. ${ }^{14,15)}$ Moreover, when the pulse duration increased beyond $350 \mu \mathrm{s}$, the average area of the single spark discharge point increased, reducing the ridge density.

The formation and structure of the rapidly resolidified layer were influenced by the silicon content (area fraction of silicon particles). For given EDM conditions, the discharge ridges increased with silicon content of the specimens (Figs. 7 and 8 ), and $M R R$ increased as with the area fraction of silicon particles. Accordingly, the area fraction governs the removal of discharge machining materials when many second-phase silicon particles are present in Al-Si alloys.

During the initial stage of the EDM process, sparks discharge between the copper electrode and the Al-Si alloy specimens. These sparks discharge at tiny ridges where conduction can most easily occur. The high temperature and discharge impact at discharge points cause specimens rapid evaporation and melting in these areas. The melting point of eutectic silicon and primary silicon was much higher than that of $\alpha-\mathrm{Al}$ in Al-Si alloys. Accordingly, some molten metal was flushed away with kerosene while some $\alpha$-Al was not flushed away from silicon particles, due to the low melting point and
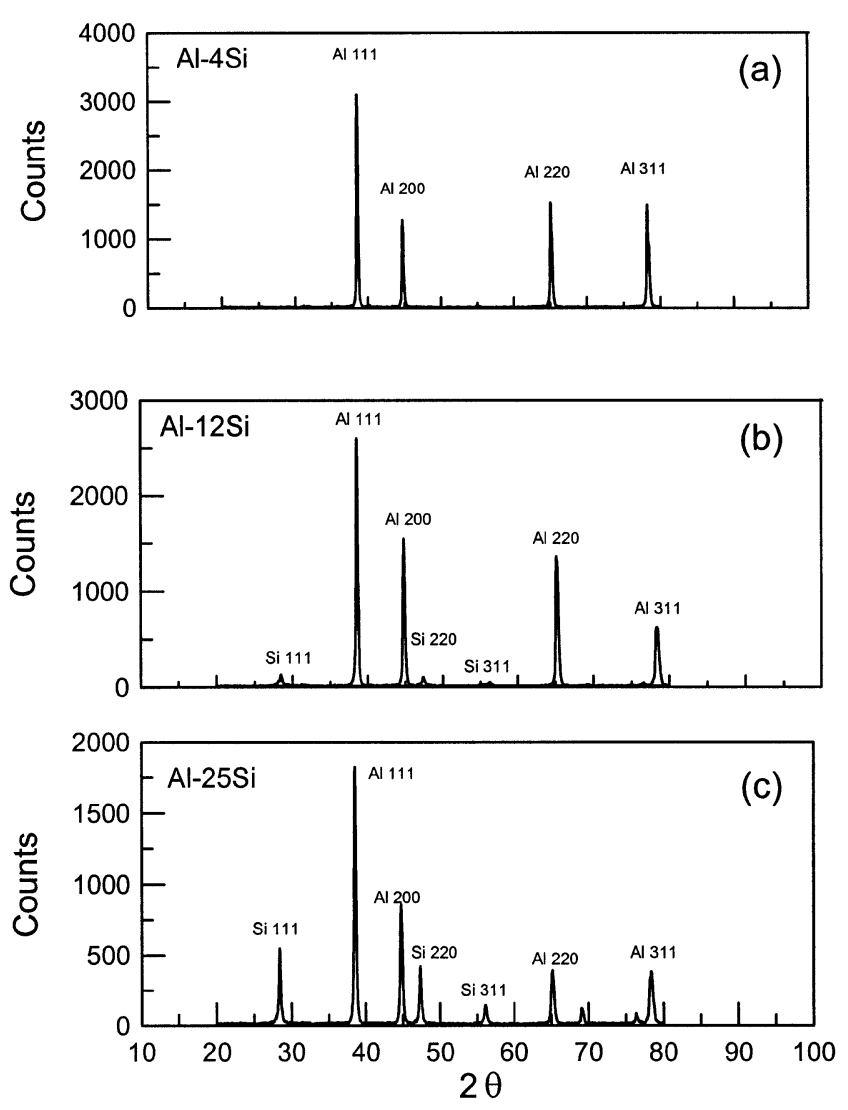

Fig. 10 X-ray diffraction patterns of EDMed surfaces with the different silicon content: (a) $4 \mathrm{Si}$, (b) $12 \mathrm{Si}$, (c) $25 \mathrm{Si}$. (a)

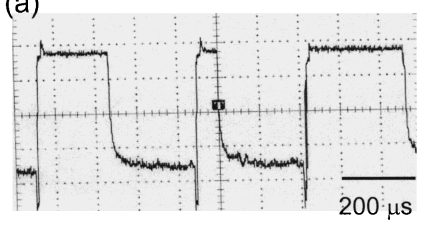

(c)

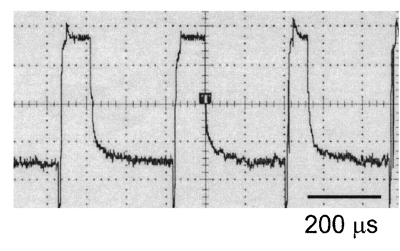

(b)

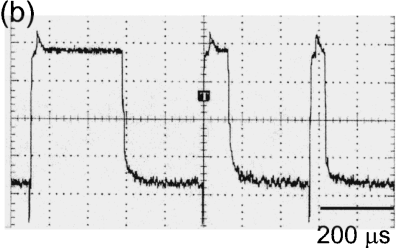

(d)

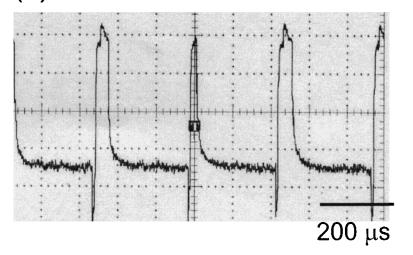

Fig. 11 Oscilloscope signals of EDM: (a) 4Si, (b) $12 \mathrm{Si}$, (c) 20Si, (d) $29 \mathrm{Si}$.

flooding of the latter, yielding ridges on the EDMed surface. Measuring the composition with Energy dispersive spectrometer (EDS) reveals that the silicon content in ridges greatly exceeds that in the microstructure (Fig. 13), and in some molten Al coated on eutectic and primary silicon particles. Therefore discharge density is linearly related to ridge density. However, for a given pulse duration $(350 \mu \mathrm{s})$, more discharge points on the base material, corresponding to a higher discharge density yields more molten metal at the discharge points. Thus, more molten metal was flushed away near the discharge points due to the increased discharge impact and the effect of machining liquid air explosion, increasing $M R R$. Notably, the duration of the single spark effect is extended with increased pulse duration. Consequently, the area of the 


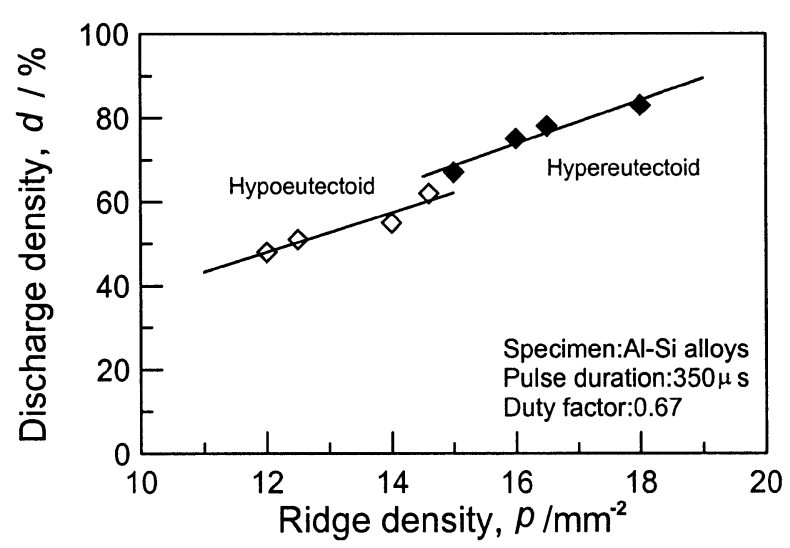

Fig. 12 Relationship between discharge density and ridge density.

discharge points is also increased, with the thickness of the resulting rapidly resolidified layers, ${ }^{12}$ ) because the re-solidified layer included almost no silicon particles.

The wearing of electrodes is inevitable during EDM; evaporation and dissolution of the copper electrode also occurs during discharge. Experimental results indicate that the EWR at shorter pulse duration, decreased as the pulse duration increased, due to frequent and severe electrode wear (Fig. 4). Previous research ${ }^{16,17)}$ has shown that this phenomenon is promoted by the heat conductivity coefficient of $\mathrm{Cu}$, which is higher than that of the specimens and is closely related to the polarity of the electrodes. For given EDM conditions, pulse duration: $350 \mu \mathrm{s}$, the discharge density of sparks increased with silicon content, as did the gap between the two poles (electrode and specimen). Removing chips and avoiding the accumulation of carbon is thus made easier. Therefore, EWR increased with the area fraction of primary silicon particles.

\section{Conclusions}

(1) The EDM parameters and the area fraction of secondphase primary silicon particles significantly affect the EDM characteristics of hypereutectic Al-Si alloys. As the pulse duration reaches its peak the removal of materials is promoted as the area fraction of primary silicon particles increases.

(2) The rapidly resolidified layers on the EDMed surface of Al-Si alloys exhibit continuous ridges. The ridge density is governed by EDM conditions and by the area fraction of silicon particles in the base materials. This density determines the removal rate of this material.

(3) The ridges formed on the EDMed surface mainly exhibits the Al-Si rapid re-solidified structure. An analysis of the sub-layer by EDS shows that the silicon content increased as approached the rapidly resolidified layers on the EDMed surface.

(4) The electrodes wear rate tended to increase with the area fraction of primary silicon particles. However, the electrode wear rate of Al-Si alloys was adversely rapidly decreased by an increase in pulse duration. The wear rate fell below $8.2 \times 10^{-8} \mathrm{~kg} / \mathrm{s}$ when the pulse duration exceeded $150 \mu \mathrm{s}$.
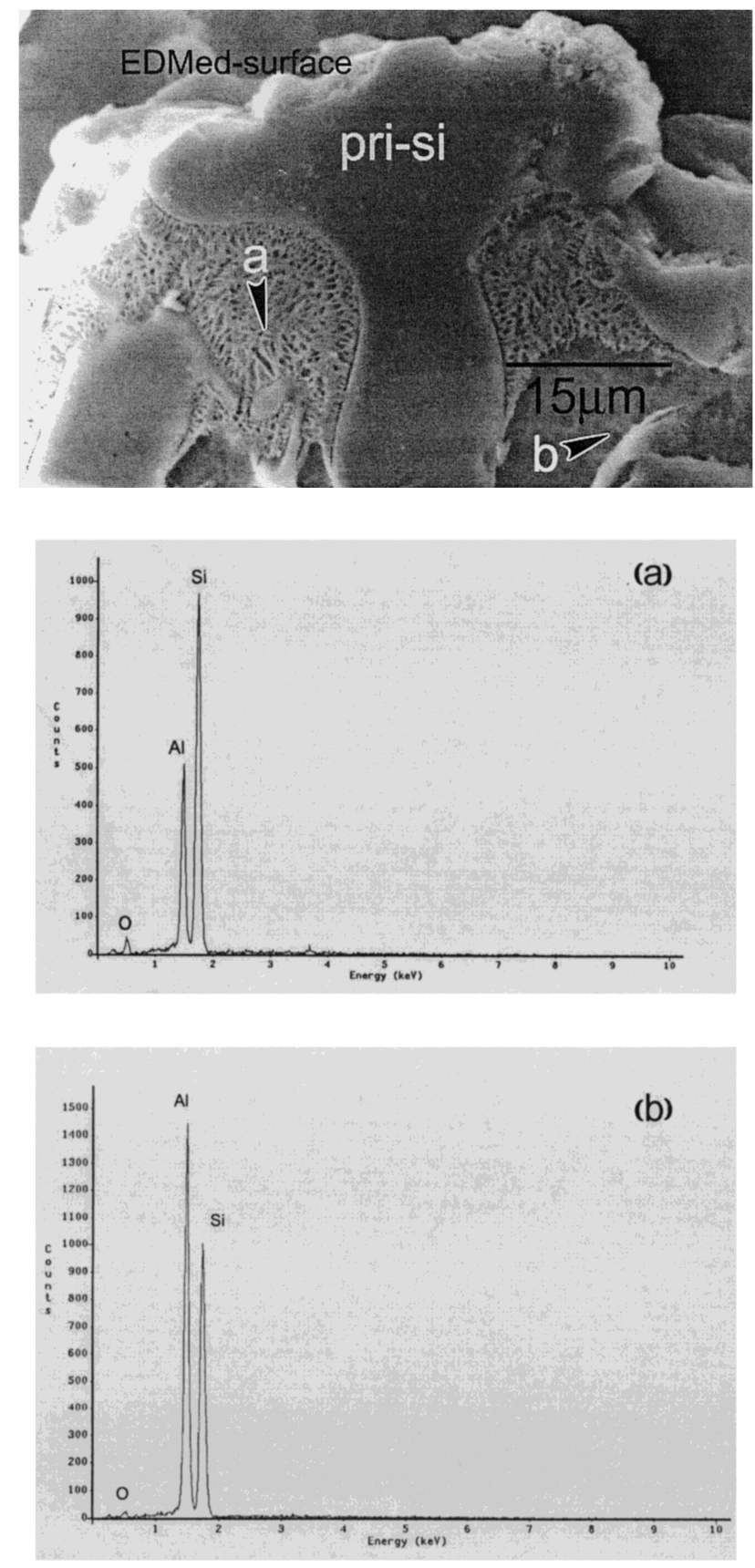

Fig. 13 EDS and microstructure of EDM sub-layers: (a) 74.3 mass\%, (b) 29.8 mass \%. (Al-29Si, pulse duration: $350 \mu \mathrm{s}$ )

\section{Acknowledgements}

The National Science Council of Taiwan, R.O.C. for which we are grateful financially supported this work (Contact No, NSC 90-2216-E-006-014).

\section{REFERENCES}

1) Metals Handbook, Alloy Phase Diagrams, Vol. 3, American Society for Metals, 10th ed., (Metals Park, Ohio, 1990) 52-55.

2) T. Takase: Imono 60 (1988) 752-756.

3) J. W. Liou, L. H. Chen and T. S. Lui: J. Mater. Sci. 30 (1995) 258-262.

4) Carl Dorsch: Cutting Tool Engineering 4 (1994) 22-28.

5) Y. Fukuzawa, Y. Kojima, T. Tani, E. Sekiguti and N. Mohri: Materials and Manufacturing Process 10 (1995) 195-203.

6) L. C. Lee, L. C. Lim, Y. S. Wong and H. H. Lu: J. Materials Processing 
Technology 24 (1990) 513-523.

7) J. Zhixn, Z. Jianhua and A. Xing: J. Materials Processing Technology $\mathbf{5 3}(1995)$ 811-816.

8) J. S. Soni: Wear 177 (1994) 71-79.

9) Y. Tsunekawa, M. Okumiya and N. Mohri: Mater. Sci. Eng. A174 (1994) 193-198.

10) H. Hocheng, W. T. Lei and H. S. Hsu: J. Materials Processing Technology 63 (1997) 813-818.

11) M. Ramulu and M. Taya: J. Mater. Sci. 24 (1989) 1103-1108.

12) D. C. Tsai, T. S. Lui and L. H. Chen: Mater. Trans., JIM 41 (2000) 293-299.
13) D. C. Tsai, T. S. Lui and L. H. Chen: AFS Trans. 107 (1999) 389-396.

14) H. Xia, H. Hashimoto, M. Kunieda and N. Nishiwaki: J. Japan Society for Precision Engineering 62 (1996) 1141-1145.

15) N. Mohri, M. Suzuki, M. Furuya and N. Saito: Annals of the CIRP 44/1 (1995) 165-168.

16) M. Motoki and K. Hashiguchi: Annals of the CIRP 14 (1967) 485-489.

17) M. R. Patel, M. A. Barrufet, P. T. Eubank and D. D. Dibitonto: J. Appl. Phys. 66 (1989) 4104-4111. 